\title{
Dysglycemia and Dyslipidemia Models in Nonhuman Primates: Part III. Type I or II Diabetogenic Effects of Streptozocin
}

\author{
Yongqiang Liu, Jiajun Gao, Xiaoli Wang, Yixin Jim Wang, Yong-Fu Xiao* \\ Cardiovascular and Metabolic Diseases, Crown Bioscience, Inc., Taicang, Jiangsu Province, China
}

\begin{abstract}
Streptozocin (STZ), a naturally occurring glucosamine-nitrosourea compound, has been used for diabetogenic induction in animals for diabetic research due to its high toxicity to pancreatic beta cells. This study was to evaluate the diabetogenic effects of STZ by multiple low doses or by single high dose in normoglycemic nonhuman primates (NHPs). Each monkey in the 1st group ( $\mathrm{n}=6$ ) was intravenously administered with 7.5 to $15 \mathrm{mg} / \mathrm{kg} \mathrm{STZ}$ once every 2 to 4 weeks until successful induction of hyperglycemia or until the end of this 28 -week study. In the 2 nd group $(\mathrm{n}=7)$ each monkey was intravenously injected with $35 \mathrm{mg} / \mathrm{kg}$ STZ once only. Plasm glucose, insulin and lipid levels were monitored weekly during the study. The hyperglycemic responses to STZ were more severe in the NHPs treated with the single high dose. Among them one animal died on the 2nd day after STZ dosing. Compared with STZ multiple low doses, single high dose caused much severe insulin depletion, similar to Type I diabetes. In addition, beta-cell sensitivity to STZ toxicity varied obviously among individual monkeys, some highly sensitive and some almost no response at all. STZ also resulted in abnormal response to the intravenous glucose tolerance test (ivGTT). These results demonstrate that hyperglycemic levels among STZ-treated animals varied and differed significantly after either single high dose or multiple low doses. Our data may help researchers to understand the diabetogenic process and variability of STZ induction in NHPs and to choose a severe or moderate model for their research.
\end{abstract}

Keywords: Nonhuman primate; Streptozocin; Diabetogenic induction; Diabetes

Abbreviation: AAALAC: Association for Assessment and Accreditation of Laboratory Animal Care; ADP: Adenosine Diphosphate; ALT: Alanine Aminotransferase; AST: Aspartate Aminotransferase; AUC: Area Under the Curve; DNA: Deoxyribonucleic Acid; EDTA: Ethylenediaminetetraacetic Acid; FDA: Food and Drug Administration; GLUT2: Glucose Transporter 2; HDL: High Density Lipoproteins; IACUC: Institutional Animal Care and Use Committee; ivGTT: Intravenous Glucose Tolerance Test; LDL: Low Density Lipoproteins; NHPs: Non-Human Primates; PBS: Phosphate Buffer Saline; SEM: Standard Error of the Mean; STZ: Streptozocin; TC: Total Cholesterol; TG: Triglycerides; T2DM: Type II Diabetes Mellitus

\section{INTRODUCTION}

Streptozocin or streptozotocin (STZ) is a naturally occurring glucosamine-nitrosourea compound. It was originally discovered as an antibiotic in a strain of the soil microbe Streptomyces achromogenes by the scientists at the drug company Upjohn (part of Pfizer lately) in the late 1950s [1]. Similar to other alkylating nitrosourea agents, its chemical property is toxic to cells via damaging DNA. Due to its similar enough to glucose, STZ can be transported into the cell by the glucose transport protein GLUT2 (glucose transporter 2), but not by the other types of glucose transporters [2,3]. This explains why STZ is highly toxic to pancreatic beta-cells because of their high expression of GLUT2. Therefore, STZ has been used in medicine for treating pancreatic beta-cell cancer by damaging DNA since 1970s [4]. STZ-induced DNA damage can activate poly ADP(adenosine diphosphate)-ribosylation which is more critical for its diabetic induction than DNA damage itself [5]. This is particularly toxic to the insulin-producing beta-cells in mammals. STZ is thus widely used for inducing hyperglycemic models in animals by single large dose or by multiple small doses [6,7]. Rossini et al. reported early that multiple small dose injections of STZ produced a delayed, progressive increase in plasma glucose in mice within 5-6 days after the injections and multiple subdiabetogenic doses or a large dose of STZ also induced hyperglycemia in rats [6]. In male cynomolgus

Correspondence to: Dr. Yong-Fu Xiao, MD, PhD, Cardiovascular and Metabolic Diseases, Crown Bioscience, Inc., 6 Beijing West Road, Taicang, Jiangsu Province, The People's Republic of China 215400, (Adjunct Professor, Department of Pharmacology, Physiology \& Neuroscience, Rutgers University-New Jersey Medical School, Newark, NJ, USA) Tel: +86-512-5387-9826; Fax: +86-512-5387-9801; E-mail: xiaoyongfu@crownbio.com

Received: February 26, 2019, Accepted: March 22, 2019, Published: March 28, 2019

Citation: Liu Y, Gao J, Wang X, Wang YJ, Xiao YF (2019) Dysglycemia and Dyslipidemia Models in Nonhuman Primates: Part III. Type I or II Diabetogenic Effects of Streptozocin. J Diabetes Metab. 10:823. doi: 10.35248/2155-6156.19.10.823

Copyright: (C) 2019 Liu Y, et al. This is an open-access article distributed under the terms of the Creative Commons Attribution License, which permits unrestricted use, distribution, and reproduction in any medium, provided the original author and source are credited. 
monkeys a single dose of $100 \mathrm{mg} / \mathrm{kg}$ (high dose) or $55 \mathrm{mg} / \mathrm{kg}$ (low dose) of STZ developed diabetes within $24 \mathrm{~h}$. Compared with relatively normal liver and kidney functions in low dose animals, liver and kidney in high-dose animals were obviously impaired and showed marked steatosis of the liver and tubular injury in the kidneys. Serum C-peptide levels in both groups decreased from 2 to $8 \mathrm{ng} / \mathrm{mL}$ before STZ to between 0.01 and $0.6 \mathrm{ng} / \mathrm{mL}$ after STZ. Over time, low-dose diabetic monkeys remained persistently hyperglycemic with negligible C-peptide stimulation by intravenous glucose [7].

Various hyperglycemic animal models have been used in diabetes research, including spontaneously developed, genetically manipulated, diet-induced and drug-caused diabetic models [8-17]. Nonhuman primates (NHPs) have shown spontaneous dysglycemia and dyslipidemia similar to the progression in humans, which makes them excellent translational models for diabetes and obesity research [12-17]. Dysglycemia is a broad term that refers to an abnormality in blood sugar levels, including hypoglycemia or hyperglycemia. Dyslipidemia refers to elevated triglycerides (TG), total or lowdensity lipoprotein (LDL) cholesterol levels, or low level of highdensity lipoprotein (HDL). Both dysglycemia and dyslipidemia can be important risk factors for coronary heart disease, stroke or fatty liver disease $[18,19]$. While rodent diabetic models have been used for elucidation of basic mechanisms of insulin action and aspects of weight regulation and metabolic control, NHPs represent crucial pre-clinical models with important similarities to human endocrine physiology that facilitate translation of experimental findings to the clinic. The spontaneously developed diabetic model in NHPs gives us an insight of the naturally occurring process of diabetes, but it may take years to show the phenotype, which raises the difficulty to monitor the disease progress. Due to limited resources of spontaneous diabetes in NHPs and/or other specific reasons, drug-induced diabetes in NHPs is also highly valuable for scientific research on diabetic etiology and its complications. STZinduced diabetes can be initiated in a short period of time and give us the relative convenience of monitoring the dynamic changes from non-diabetes to diabetes. In addition, islet transplantation is an attractive treatment of diabetes, especially Type I. STZ-induced Type I diabetes in NHPs is one suitable model for evaluating the effectiveness of islet transplantation. The usefulness and limitations of the STZ model in NHPs in islet transplantation were reviewed and elucidated in the previous studies $[17,20]$.

In this study we reported the diabetogenic models in NHPs induced by STZ administration either with one single high dose or with multiple low doses. The models were characterized and differences among individual animals during STZ induction were summarized. The data may help other researchers to understand the STZ induction process and its characteristics in NHPs when they replicate or use the models for diabetic research.

\section{METHODS}

\section{Animals and animal care}

Experiments were performed in normoglycemic rhesus (Macaca mulatta, $\mathrm{n}=7$ ) and cynomolgus (Macaca fascicularis, $\mathrm{n}=6$ ) monkeys with either genders (Table 1). These monkeys were individually housed and maintained in our animal facility in accordance with the guidelines approved by the Association for Assessment and Accreditation of Laboratory Animal Care (AAALAC). The room temperature was maintained at $\sim 21^{\circ} \mathrm{C}$ with a $12 \mathrm{hr}$ light/dark cycle
Table 1: General characteristics of the NHPs enrolled in the study.

\begin{tabular}{lcc}
\hline & Multiple low doses & Single high dose \\
\cline { 2 - 3 } & Cynomolgus & Rehsus \\
\cline { 2 - 3 } & $\mathbf{n}=6$ (M/F, 6/0) & $\mathbf{n}=7$ (M/F, 4/3) \\
\hline Age (year) & $12.6 \pm 1.5$ & $8.1 \pm 1.1$ \\
\hline Body weight $(\mathrm{kg})$ & $7.0 \pm 0.4$ & $9.0 \pm 0.8$ \\
\hline Glucose $(\mathrm{mg} / \mathrm{dL})$ & $79.9 \pm 2.3$ & $66.7 \pm 4.5$ \\
\hline Insulin $(\mathrm{mIU} / \mathrm{L})$ & $59.0 \pm 28.8$ & $24.5 \pm 7.0$ \\
\hline TG $(\mathrm{mg} / \mathrm{dL})$ & $33.1 \pm 7.7$ & $47.8 \pm 13.8$ \\
\hline TC $(\mathrm{mg} / \mathrm{L})$ & $118.2 \pm 8.4$ & $149.8 \pm 15.7$ \\
\hline HDL-c $(\mathrm{mg} / \mathrm{L})$ & $52.3 \pm 6.7$ & $54.1 \pm 3.9$ \\
\hline LDL-c $(\mathrm{mg} / \mathrm{L})$ & $42.2 \pm 6.1$ & $71.1 \pm 11.0$ \\
\hline
\end{tabular}

Note: $\mathrm{M} / \mathrm{F}$, male/female. There are no statistical differences between the corresponding parameters from two animal groups.

with lights off from 7 PM to 7 AM. All the animals were free access ad libitum to water and a complete, nutritionally balanced normal diet (Beijing Keao Xieli Feed Co., LTD, Beijing, China) enriched with seasonal fruit and vegetables. The experimental protocol was approved by the Institutional Animal Care and Use Committee (IACUC) of Crown Bioscience, Inc (Approval \#: AN-1308-01619 and AN-1702-009-6). Body weight was measured under either anesthesia or conscious. If under conscious, each monkey sits in a specific monkey chair for the weight measurement.

\section{STZ dosing}

The process of STZ-induced hyperglycemia was similar to others previously reported in monkey models. In the multiple low dose group, normoglycemic cynomolgus monkeys $(n=6)$ were intravenously injected with STZ (Lot S0130, Sigma, USA) at $15 \mathrm{mg} / \mathrm{kg}(15 \mathrm{mg} / \mathrm{mL}$ dissolved in the phosphate buffer saline (PBS) solution) once every 4 weeks with a total of 8 times for hyperglycemic induction (Figure 1, bold arrows). From week 4 to 28 additional STZ at $7.5 \mathrm{mg} / \mathrm{kg}$ was intravenously administered once every 4 weeks with a total of 6 times during the study (Figure 1 , dashed arrows). If hyperglycemia was successfully induced, the hyperglycemic animal was no further STZ treatment from that time point. The animals with multiple low doses were not sacrificed at the end of the study.

In the single high dose group normoglycemic rhesus monkeys $(n=7)$ were intravenously injected once with STZ (Lot S0130, Sigma, USA) at $35 \mathrm{mg} / \mathrm{kg}(35 \mathrm{mg} / \mathrm{mL}$ in PBS) for diabetes induction (Figure 1). The experimental animals were euthanized on day $7(n=4)$ and day $14(\mathrm{n}=2)$, except one death on the $2^{\text {nd }}$ day after STZ dosing.

\section{Plasma collection}

Before bleeding, each animal was fasted overnight for approximately 16 hours. Blood with a volume of 2 to $3 \mathrm{~mL}$ was collected into a K2-EDTA (K2-ethylenediaminetetraacetic acid) tube from one cephalic or saphenous vein. The sample tube was gently inverted for 10 times and then immediately placed on ice. Plasma was separated by centrifugation at $3000 \mathrm{rpm}$ for $15 \mathrm{~min}$ at $4^{\circ} \mathrm{C}$. Plasma glucose, insulin, TG, total cholesterol (TC), HDL, LDL, alanine aminotransferase (ALT), aspartate aminotransferase (AST) were analyzed in the clinical lab (The ADVIA $® 2400$ Clinical Chemistry System, The First People's Hospital of Taicang, Taicang, Jiangsu Province, China). 


\section{Intravenous glucose tolerance test (ivGTT)}

To evaluate the scale and function of beta-cells ivGTT was performed in the experimental monkeys before and after STZ treatment according to the method reported previously [21,22]. Each experimental animal was fasted overnight for approximately $16 \mathrm{hrs}$ and then anesthetized intramuscularly with initial $10 \mathrm{mg} /$ kg ketamine (Fujian Gutian Pharmaceutical Co. Ltd., Fujian, China) plus additional $5 \mathrm{mg} / \mathrm{kg}$ lately as needed during ivGTT. The cephalic and/or saphenous veins were cannulated separately for glucose infusion and blood collection. Glucose $(0.25 \mathrm{~g} / \mathrm{kg}=0.5$ $\mathrm{mL} / \mathrm{kg}$ of $50 \%$ dextrose) was intravenously infused during $30 \mathrm{sec}$ and the infusion system was then flushed with $5 \mathrm{~mL}$ heparinized $0.9 \%$ saline to push the residual glucose into the blood stream. Blood was collected from another vein into heparinized tubes prechilled on ice at the time points of immediately before (time 0 ) and then $3,5,7,10,15,20$ and 30 min after glucose infusion. Plasma was then separated and stored at $-80^{\circ} \mathrm{C}$ for subsequent assays lately.

\section{DATA COLLECTION AND STATISTICS}

The data, such as age, body weight and blood chemistry assay, were collected and tabulated. The changes of plasma glucose and insulin were measured and recorded according to experimental grouping. The area under the curve (AUC) was calculated using the first measurement $(t=0)$ as reference (M1 method) as described previously [23]. All the data were expressed as mean \pm standard error of the mean (SEM). Statistical analysis was performed by using unpaired student t-test for comparison of two means. A p-value less than 0.05 was considered to be statistically significant.

\section{RESULTS}

Plasma glucose levels were significantly increased in the NHPs treated with STZ of either multiple low doses (Figure 2) or single high dose (Figure 2). The baseline glucose levels were $79.9 \pm 2.3 \mathrm{mg} /$ $\mathrm{dL}$ and $66.7 \pm 4.5 \mathrm{mg} / \mathrm{dL}$ (Table 1) and then increased to $140.6 \pm$ $31.0 \mathrm{mg} / \mathrm{dL}$ and $253.3 \pm 55.5 \mathrm{mg} / \mathrm{dL}$ in the animals after treatment with multiple low doses or single high dose, respectively (Figure 2). In the meantime, plasma insulin concentrations were significantly decreased in the animals received STZ single high dose. Plasma insulin levels were also decreased, but not significantly $(\mathrm{p}=0.07)$, in the animals received STZ multiple low doses. The plasma TG levels
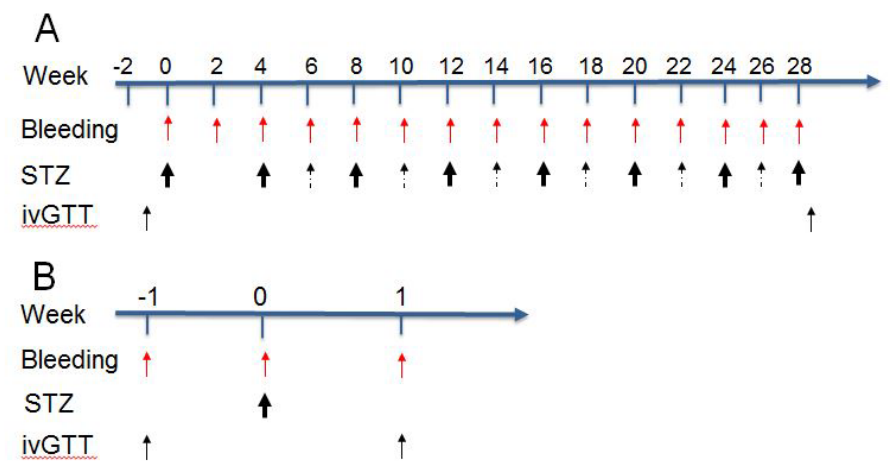

Figure 1: Flow chart of the experimental procedures. A, Multiple doses in cynomolgus monkeys $(\mathrm{n}=6)$. STZ at $15 \mathrm{mg} / \mathrm{kg}$ was intravenously injected once every 4 weeks (bold arrows). One additional STZ at $7.5 \mathrm{mg} /$ $\mathrm{kg}$ was intravenously administered every 4 weeks starting from week 4 to 28 (dashed arrows). STZ treatment was aborted in an animal from the time point when hyperglycemia was successfully induced. B, Single dose in rhesus monkeys $(\mathrm{n}=7)$. STZ at $35 \mathrm{mg} / \mathrm{kg}$ was intravenously injected in single bolus with animal termination in 14 days after dosing.

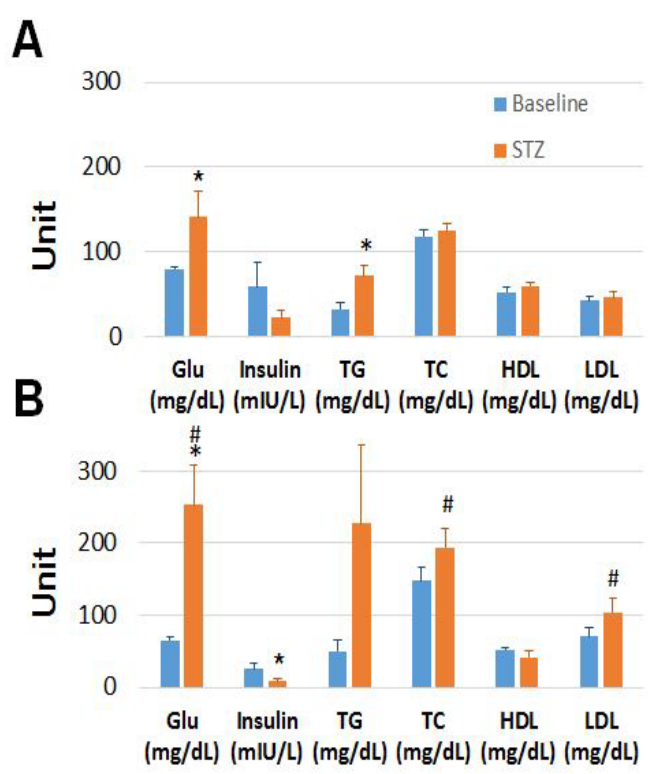

Figure 2: Changes of plasma glucose (Glu), insulin, TG, TC, HDL and LDL in the monkeys treated with STZ of either multiple low doses (A) or single high dose (B). The parameters were measured at the time just before STZ dosing as baselines (blue bars) and after the last dosing of STZ multiple low doses (A, orange bars) or day 7 after STZ single high dose (B, orange bars). *,$p<0.05$, versus the corresponding baseline; \#, $p<0.05$, versus the group treated with STZ multiple low doses.

were significantly increased accompanied with less obvious changes on TC, HDL, LDL levels in the group treated with STZ multiple low doses (Figure 2). In addition, plasma glucose, TC and LDL were significantly higher in the animals treated with STZ single high dose than in the monkeys received STZ multiple low doses (Figure 2).

To evaluate the effects of STZ on insulin production, ivGTTs were performed before and after STZ treatment in the experimental monkeys. The results obtained from the animals received multiple STZ low doses show the baseline glucose level was increased and ivGTT responsive curve was raised to a high level (Figure 3). Compared with pre-treatment, insulin responses to ivGTT in the animals with STZ multiple low doses were smaller during ivGTT. Plasma glucose and insulin levels responded to ivGTT even more obviously in the monkeys received STZ single high dose, compared with STZ pretreatment (Figure 3).

The AUC data show that the plasma glucose levels increased and insulin concentrations were decreased in the animals treated with STZ multiple low doses, but the changes were not statistically significant $(p>0.05$, Figure 3 ). The $K$ value of body glucose handling was also decreased, but still not statistically significant ( $p=0.06$, Figure 3, middle panel) after treatment with STZ multiple low doses. However, in the monkeys treated with STZ single high dose the increase in glucose AUC and decrease in glucose K value, as well as the decrease in insulin AUC were statistically significant $(\mathrm{p}<0.05$, Figure 3).

The changes of plasma glucose and insulin occurred gradually in the monkeys treated with STZ multiple low doses. Plasma glucose levels of one monkey (ID\# C2, $\mathbf{\square}$ ) were markedly increased after two STZ treatments on day 0 and 28 and then increased continuously even without further STZ treatment (Figure 4). Plasma glucose levels of another monkey (ID\# C3, $\diamond$ ) were markedly increased after four STZ treatments on day 0, 28, 42 and 56 and then increased continuously even without further STZ treatment (Figure 4, 
A

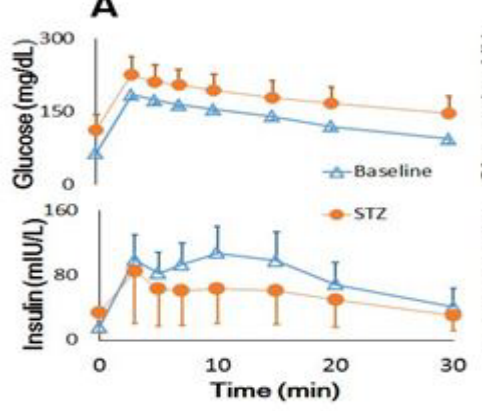

B
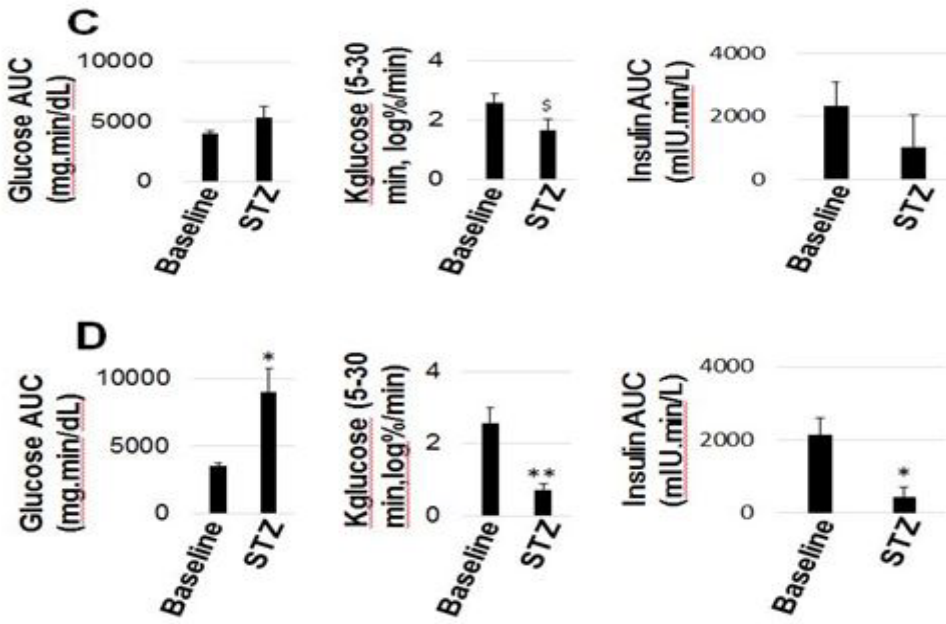

Figure 3: Effects of STZ on insulin production during ivGTT. The tests were performed in the experimental monkeys received either STZ multiple low doses (A) or STZ single high dose (B). The tests were conducted at the times before STZ dosing as the baselines (triangles) and after the last dosing of STZ multiple low doses (A, solid cycles) or day 7 after STZ single high dose (B, solid cycles). Compared with pre-treatment, glucose responses to ivGTT were markedly increased and insulin responses were decreased in the animals with STZ multiple low doses (A and C) or single high dose (B and D). AUC, the area under the curve; Kglucose, the decay of ivGTT glucose curve representing the body capability of glucose handling. ${ }^{*}, p>0.05 ;{ }^{* *}, p<0.01 ; \$, p=0.06$, versus the corresponding baseline.
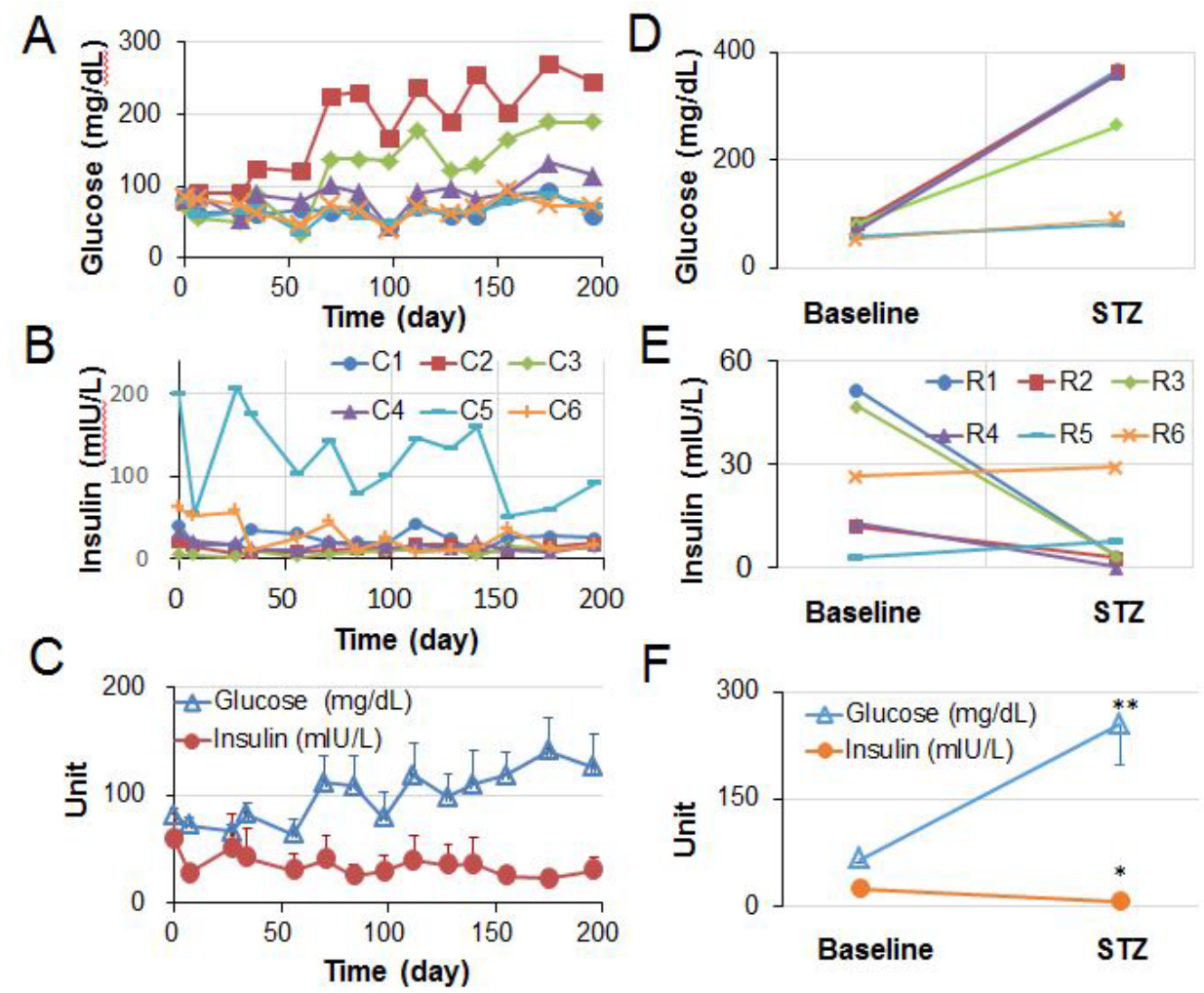

Figure 4: Time courses of the changes of plasma glucose and insulin. Plasma glucose (A) and insulin (B) levels of the individual monkeys were plotted against the time after STZ treatment with multiple low doses. Panel C shows the changes of the average glucose and insulin levels in the animals during STZ multiple low doses. Other panels show the changes of plasma glucose (D) and insulin (E) levels of individual monkeys and the means \pm SEs of plasma glucose and insulin levels (F) of the animals received STZ single high dose. ${ }^{*}, p<0.05 ;{ }^{* *}, p<0.01$; vs the corresponding baseline (F). 
Table 2: Changes of body weight, plasma glucose and insulin levels, as well as the total amount of STZ administered.

\begin{tabular}{|c|c|c|c|c|c|c|c|c|c|c|}
\hline \multirow{2}{*}{$\begin{array}{l}\text { Animal } \\
\text { ID }\end{array}$} & \multirow{2}{*}{$\begin{array}{l}\text { Age } \\
\text { (year) }\end{array}$} & \multicolumn{2}{|c|}{ Body weight $(\mathrm{kg})$} & \multicolumn{2}{|c|}{ Glucose $(\mathrm{mg} / \mathrm{dL})$} & \multicolumn{2}{|c|}{ Insulin (mIU/L) } & \multicolumn{2}{|c|}{ C-peptide (nmol/L) } & \multirow{2}{*}{$\frac{\mathrm{STZ}}{\mathrm{mg} / \mathrm{kg} \times \text { dosing \# }}$} \\
\hline & & Baseline & STZ & Baseline & STZ & Baseline & STZ & Baseline & STZ & \\
\hline $\mathrm{C} 1$ & 17 & 6.2 & 6.3 & 86.2 & 58.7 & 40.9 & 26 & 0.67 & 0.67 & $\begin{array}{c}15 \mathrm{mg} / \mathrm{kg} \times 8+7.5 \mathrm{mg} / \mathrm{kg} \times \\
7=172.5 \mathrm{mg} / \mathrm{kg}\end{array}$ \\
\hline $\mathrm{C} 2$ & 10 & 8 & 7.4 & 79 & 243.9 & 19.4 & 18.4 & 0.49 & 0.44 & $15 \mathrm{mg} / \mathrm{kg} \times 2=30 \mathrm{mg} / \mathrm{kg}$ \\
\hline $\mathrm{C} 3$ & 17 & 7.6 & 7.8 & 70.4 & 189.2 & 4.6 & 13.5 & 0.21 & 0.46 & $\begin{array}{c}15 \mathrm{mg} / \mathrm{kg} \times 3+7.5 \mathrm{mg} / \mathrm{kg} \times \\
1=52.5 \mathrm{mg} / \mathrm{kg}\end{array}$ \\
\hline $\mathrm{C} 4$ & 10 & 6.7 & 6.6 & 81.9 & 115.9 & 30.4 & 16.7 & 0.9 & 0.58 & $\begin{array}{c}15 \mathrm{mg} / \mathrm{kg} \times 7+7.5 \mathrm{mg} / \mathrm{kg} \times \\
6=150 \mathrm{mg} / \mathrm{kg}\end{array}$ \\
\hline C5 & 11 & 8.3 & 8 & 77.2 & 71.5 & 197.8 & 91.8 & 2.06 & 1.09 & $\begin{array}{c}15 \mathrm{mg} / \mathrm{kg} \times 8+7.5 \mathrm{mg} / \mathrm{kg} \times \\
7=172.5 \mathrm{mg} / \mathrm{kg}\end{array}$ \\
\hline C6 & 17 & 5.6 & 5.7 & 84.4 & 71.6 & 60.7 & 16.2 & 0.9 & 0.62 & $\begin{array}{c}15 \mathrm{mg} / \mathrm{kg} \times 8+7.5 \mathrm{mg} / \mathrm{kg} \times \\
7=172.5 \mathrm{mg} / \mathrm{kg}\end{array}$ \\
\hline $\mathrm{n}$ & 6 & 6 & 6 & 6 & 6 & 6 & 6 & 6 & 6 & \\
\hline Mean & 13.7 & 7 & 7 & 79.9 & 125.1 & 59 & 30.4 & 0.87 & 0.64 & \\
\hline SE & 1.5 & 0.4 & 0.4 & 2.3 & 30.8 & 28.8 & 12.4 & 0.26 & 0.1 & \\
\hline
\end{tabular}

Note: Baseline, the results were collected before STZ induction; STZ, the results were collected during the last week near the end of the study.

Table 2). The $3^{\text {rd }}$ animal (ID\# C4, $\mathbf{\Delta}$ ) also showed some increases in plasma glucose at the very late stage ( $>154$ days) after treatment with STZ multiple low doses (Figure 4). Figure 4 shows the time course of the changes of plasma insulin levels of individual animals (Figure 4) and the means \pm SEs of plasma glucose and insulin levels in the animals who received STZ multiple low doses (Figure 4, Table 2). Other panels in Figure 4 shows the changes of plasma glucose (4D) and insulin (4E) levels of individual animals treated with STZ single high dose. Single high dose of $35 \mathrm{mg} / \mathrm{kg} \mathrm{STZ}$ caused hyperglycemia (>200 mg/dL) in five (including the death one on the $2^{\text {nd }}$ day after STZ treatment) out of seven animals with $71 \%$ diabetogenic induction. Figure 4 shows the means \pm SEs of plasma glucose and insulin levels of the animal group received STZ single high dose. Clearly, both glucose and insulin levels were significantly changed after single high dose of STZ at $35 \mathrm{mg} / \mathrm{kg}$ (Figure 4).

\section{DISCUSSION AND CONCLUSION}

In this study STZ with two dosing approaches was used to induce hyperglycemia in nonhuman primates. Our data show that the hyperglycemic effect of STZ was more severe in the monkeys treated with the single high dose than those treated with the multiple low doses (Figure 2). In addition, the sensitivity to STZ varied markedly among the treated individual monkeys (Figure 4). High STZ-sensitive animal could die shortly after administration of one single high dose at $35 \mathrm{mg} / \mathrm{kg}$. In contrast, low sensitive monkeys could be much less or no response to STZ, even with multiple low doses in a total of $172.5 \mathrm{mg} / \mathrm{kg}$ (Figure 4, Table 2). Our results demonstrate that the responses to STZ vary individually in NHPs and extra caution may need to be taken to avoid incidental death if single high dose is administered.

STZ is widely used to induce a reproducible form of diabetes in NHPs [24]. Different dosages of STZ have been used to induce diabetes in nonhuman primates [25,26]. Litwak et al. tried to induce diabetes in cynomolgus monkeys using a dose of $30 \mathrm{mg} /$ $\mathrm{kg}$ and found that it did not reliably cause diabetes [25]. Only three of eight animals became mildly hyperglycemic and the rest had to be given a second dose of STZ [25]. Stegall et al. reported that $80 \%$ of cynomolgus monkeys became diabetic after $50 \mathrm{mg} /$ $\mathrm{kg} \mathrm{STZ}$ and remained hyperglycemic for up to 1 year [27]. Another study with cynomolgus monkeys by using $55 \mathrm{mg} / \mathrm{kg}$ of STZ showed $100 \%$ diabetogenic effects for up to 1 year without any evidence of regeneration of the beta-cells [28]. The diabetogenic effects of STZ were also examined in rhesus monkeys at 30, 45 or $60 \mathrm{mg} / \mathrm{kg}$ [29]. The animals received $30 \mathrm{mg} / \mathrm{kg} \mathrm{STZ} \mathrm{had} \mathrm{normal}$ glucose tolerance. Five out of seven monkeys treated with $45 \mathrm{mg} /$ $\mathrm{kg}$ developed hyperglycemia, and two out of two animals received $60 \mathrm{mg} / \mathrm{kg}$ developed hyperglycemia [29]. Our results from the rhesus monkeys using single high dose of $35 \mathrm{mg} / \mathrm{kg}$ of STZ showed that five (including the death one on the $2^{\text {nd }}$ day after STZ treatment) out of seven animals developed hyperglycemia (>200 $\mathrm{mg} / \mathrm{dL}$, Figure 4). However, the data from cynomolgus monkeys received the multiple low doses of STZ showed three out of six animals (50\%) developed hyperglycemia (>100 mg/dL, Figure 4). Among the three diabetogenic animals two showed hyperglycemia within 8 weeks and another one showed hyperglycemia nearly 22 weeks after multiple low doses. The rest three non-diabetogenic monkeys failed to response to multiple low doses of STZ, even with a total of $172.5 \mathrm{mg} / \mathrm{kg} \mathrm{STZ}$ (Table 2). These results indicate that there are obvious variations among nonhuman primates in their responses to STZ.

The underline mechanism or cause of such obvious variability in NHPs responded to STZ is not fully delineated. The previous reports showed that diabetogenic dose of STZ depended on the animal species, age, body weight, route of administration, and nutritional status [30-32]. In addition, the individual genetic, healthy and physiological differences, such as receptor expression levels, may also contribute to the wide variance in STZ dose levels and responses among experimental animals. Another reason for these discrepancies could be that the beta-cells of some monkeys are more resistant to the toxic effect of STZ than those of other monkeys, which may account for the varying STZ dosages and responses to the diabetogenic effects. For example, insulin producing cells that do not express GLUT2 transporter in the plasma membrane are resistant to STZ toxicity and only become vulnerable to STZ toxicity after expression of GLUT2 protein in the plasma membrane [33]. In addition, Bottino et al. reported that the pancreas in 2 out of 11 STZ diabetic monkeys could regain endogenous $\mathrm{C}$-peptide production after complete beta-cell destruction by high-dose STZ injection $(125-150 \mathrm{mg} / \mathrm{kg}$ body 
weight) [34]. Higher doses of STZ (>80 mg/ $\mathrm{kg}$ body weight) were found to be effective and sufficient to produce the diabetogenic effects in NHPs [35-39] but were associated with more systemic side effects (e.g., transient vomiting, severe hypoglycemia) and serious complications (e.g., hepatic and renal function/tissue injury), as well as higher morbidity and mortality (approximately 29\%-100\%) [38,40-43]. In vervet monkeys (Chlorocebus aethiops) intravenous administration of either 45 or $55 \mathrm{mg} / \mathrm{kg}$ STZ had $15 \%$ mortality, likely secondary to renal toxicity [44]. Twice-daily insulin therapy was initiated to maintain comparable glycemic control and then exogenous insulin requirements increased rapidly for 4 weeks; STZ $(45 \mathrm{mg} / \mathrm{kg})$ insulin doses stabilized thereafter while STZ $(55 \mathrm{mg} / \mathrm{kg})$ doses continued to increase through 16 weeks. The lower dose of STZ $(45 \mathrm{mg} / \mathrm{kg}$ ) significantly improved the toxicity profile without altering efficacy in inducing diabetes. Sufficient time following induction is recommended to allow transient renal, hepatic and hematologic parameters to resolve [44]. Therefore, to successfully establish the STZ-induced diabetic model in NHPs, an optimal dose or feasible approach is necessary. Such dose or approach can induce irreversible and stable diabetes with much less adverse effects and more similar to type II diabetes. Our present study provides some insights on the model induction in NHPs, because approximately $50 \%$ monkeys treated with multiple low doses of STZ were hyperglycemic without any observable side effects and the need of exogenous insulin therapy.

In summary, the current study compared the diabetogenic effects of STZ in NHPs treated with either single high dose or multiple low doses. Our data demonstrate single high doses of STZ result in more severe diabetogenic effects (similar to type I) than multiple low doses (similar to Type II). Single high doses of STZ are accompanied more serious side effects, including insulin dependence, live damage, kidney impairment and animal death. In contrast, no obvious side effects are observed in NHPs received multiple low doses of STZ. As NHPs are highly valuable in diabetic research, doses and administration manners of STZ may help to select a diabetogenic model for evaluating new compounds or therapeutic interventions. For example, single high dose of STZ can induce Type I model for beta-cell or islet transplantation and multiple low doses induce Type II model for anti-diabetic drug test.

\section{DECLARATIONS}

\section{Research involving human participants and/or animals}

The study protocol and experimental procedures used in this study were approved by the IACUC of Crown Bioscience Inc., which includes member from outside of the company. The approval numbers are AN-1308-016-19 and AN-1702-009-6.

\section{CONFLICTS OF INTEREST}

All of the authors are employee of Crown Bioscience Inc. The authors declare no conflict of interest in this study.

\section{INFORMED CONSENT}

All the authors have read and approved the manuscript for submission. Their consents are available if requested.

\section{Availability of data and material}

All the materials and relevant raw data supporting our findings can be found in Tables and Figures in the manuscript and are freely available to readers or scientists wishing to use them for noncommercial purposes.

\section{Funding}

This study was supported by the internal research fund from Crown Bioscience Inc.

\section{AUTHORS' CONTRIBUTIONS}

Y Liu, J Gao and X Wang conducted the study and data collection. Y Liu, Y (Jim) Wang and Y-F Xiao participated study design, data analysis, figure and manuscript preparation.

\section{ACKNOWLEDGEMENTS}

We are grateful to our animal center for their professional care of the animals and for their excellent technical assistances during the study.

\section{REFERENCES}

1. Vavra JJ, Deboer C, Dietz A, Hanka LJ, Sokolski WT. Streptozotocin, a new antibacterial antibiotic. Antibiot Annu. 1959;7:230-235.

2. Wang Z, Gleichmann H. GLUT2 in pancreatic islets: crucial target molecule in diabetes induced with multiple low doses of streptozotocin in mice. Diabetes. 1998;47:50-56.

3. Schnedl WJ, Ferber S, Johnson JH, Newgard CB. STZ transport and cytotoxicity. Specific enhancement in GLUT2-expressing cells. Diabetes. 1994:43:1326-1333.

4. Murray-Lyon IM, Eddleston AL, Williams R, Brown M, Hogbin BM, Bennett A, et al. Treatment of multiple-hormone-producing malignant islet-cell tumour with streptozotocin. Lancet. 1968;2:895-898.

5. Szkudelski T. The mechanism of alloxan and streptozotocin action in beta cells of the rat pancreas. Physiol Res. 2001;50:537-546.

6. Rossini AA, Like AAA, Chick WL, Appel MC, Cahill GF Jr. Studies of streptozotocin-induced insulitis and diabetes Proc Natl Acad Sci USA. 1977;74:2485-2489.

7. Koulmanda M, Qipo A, Chebrolu S, O'Neil J, Auchincloss H, Smith $\mathrm{RN}$. The effect of low versus high dose of streptozotocin in cynomolgus monkeys (Macaca fascilularis). Am J Transplant. 2003;3:267-272.

8. King AJ. The use of animal models in diabetes research. Br J Pharmacol. 2012;166:877-894.

9. Sasase T, Pezzolesi MG, Yokoi N, Yamada T, Matsumoto K (2013) Animal models of diabetes and metabolic disease. J Diabetes Res 2013: 281928.

10. Chatzigeorgiou A, Halapas A, Kalafatakis K, Kamper E. The use of animal models in the study of diabetes mellitus. In Vivo. 2009;23:245 258.

11. Islam MS. Animal models of diabetic neuropathy: progress since 1960 s. J Diabetes Res. 2013;2013:149452.

12. Wang X, Wang B, Sun G, Wu J, Liu Y, Wang YJ, et al. Dysglycemia and Dyslipidemia Models in Nonhuman Primates: Part I. Model of Naturally Occurring Diabetes. J Diabetes Metab. 2015;S13:010.

13. Wang B, Sun G, Liu Y, Qiao J, Ye W, Wang H, et al Dysglycemia and Dyslipidemia Models in Nonhuman Primates: Part II. Model of Naturally Occurring or Experimental Obesity. J Diabetes Metab. 2016;6:641.

14. Wagner JD, Cline JM, Shadoan MK, Bullock BC, Rankin SE, Cefalu WT. Naturally occurring and experimental diabetes in cynomolgus 
monkeys: a comparison of carbohydrate and lipid metabolism and islet pathology. Toxicol Pathol. 2001;29:142-148.

15. Harwood HJ, Listrani P, Wagner JD. Nonhuman primates and other animal models in diabetes research. J Diabetes Sci Technol. 2012;6:503. 514 .

16. Wagner JD, Kavanagh K, Ward GM, Auerbach BJ, Harwood HJ Jr, Kaplan JR. Old World Nonhuman Primate Models of Type 2 Diabetes Mellitus. Oxford Journals Science \& Mathematics ILAR. 2006;47:259271.

17. Zhu H, Yu L, He Y, Wang B. Nonhuman primate models of type 1 diabetes mellitus for islet transplantation. J Diabetes Res. 2014;2014:785948

18. Speliotes EK, Massaro JM, Hoffmann U, Vasan RS, Meigs JB, Sahani DV, et al. Fatty Liver is Associated With Dyslipidemia and Dysglycemia Independent of Visceral Fat: The Framingham Heart Study. Hepatology. 2010;51:1979-1987.

19. Rydén L, Mellbin L. New Hope For People With Dysglycemia and Cardiovascular Disease Manifestations Reduction of Acute Coronary Events With Pioglitazone. Circulation. 2017;135:1894-1896.

20.Contreras JL, Smyth CA, Curiel DT, Eckhoff DE. Nonhuman primate models in type 1 diabetes research. ILAR J. 2004;45:334-342.

21. Hansen BC. Investigation and treatment of type 2 diabetes in nonhuman primates. Methods Mol Biol. 2012;933:177-185.

22. Hansen BC, Bodkin NL. Standardization of IVGTT. Importance of method used to calculate glucose disappearance. Diabetes care. 1993; 16:847.

23.Wang X, Hansen BC, Shi D, Fang Y, Du F, Wang B, et al. Quantification of beta-cell insulin secretory function using a graded glucose infusion with C-peptide deconvolution in dysmetabolic, and diabetic cynomolgus monkeys. Diabetol Metab Syndr. 2013;5:40.

24.He S, Wang D, Wei L. Practical and critical instruction for nonhuman primate diabetic models. Transplant Proc. 2013;45:1856-1865.

25.Litwak KN, Cefalu WT, Wagner JD. Streptozotocin-induced diabetes mellitus in cynomolgus monkeys: changes in carbohydrate metabolism, skin glycation, and pancreatic islets. Lab Anim Sci. 1998;48:172-178.

26. Theriault BR, Thistlethwaite JR Jr, Levisetti MG, Wardrip CL, Szot G, David BS, et al. Induction, maintenance, and reversal of streptozotocininduced insulin-dependent diabetes mellitus in the juvenile cynomolgus monkey (Macaca fascilularis). Transplantation. 1999;68:331-337.

27. Stegall MD, Chabot J, Weber C, Reemtsma K, Hardy MA. Pancreatic islet transplantation in cynomolgus monkeys. Initial studies and evidence that cyclosporine impairs glucose tolerance in normal monkeys. Transplantation. 1989;48:944-950.

28. Koulmanda M, Oipoa A, Chebrolua S, O'Neilb J, Auchincloss H Jr, Smith RN. The Effect of Low Versus High Dose of Streptozotocin in Cynomolgus Monkeys (Macaca Fascilularis). Am J Transplant. 2003;3:267-272.

29.Pitkin RM, Reynolds WA. Diabetogenic effects of streptozotocin in rhesus monkeys. Diabetes. 1970;19:85-90.

30.Sakata N, Yoshimatsu G, Tsuchiya H, Egawa S, Unno M. Animal models of diabetes mellitus for islet transplantation. Exp Diabetes Res. 2012;2012:11.
31. Eleazu CO, Eleazu KC, Chukwuma S, Essien UN. Review of the mechanism of cell death resulting from streptozotocin challenge in experimental animals, its practical use k to humans. J Diabetes Metab Disord. 2013;12:60.

32.Hayashi K, Kojima R, Ito M. Strain differences in the diabetogenic activity of streptozotocin in mice. Biol Pharm Bull. 2006;29:1110-1119.

33.Elsner M, Guldbakke B, Tiedge M, Munday R, Lenzen S. Relative importance of transport and alkylation for pancreatic beta-cell toxicity of streptozotocin. Diabetolgia. 2007;43:1528-1533.

34. Bottino R, Criscimanna A, Casu A, He J, der Windt DJV, Rudert WA, et al. Recovery of endogenous beta-cell function in nonhuman primates after chemical diabetes induction and islet transplantation. Diabetes. 2009;58:442-447.

35.Thompson P, Badell IR, Lowe M, Turner A, Cano J, Johnson B, et al. Alternative immunomodulatory strategies for xenotransplantation: CD40/154 pathway-sparing regimens promote xenograft survival. The American Journal of Transplantation. 2012;12:1765-1775.

36.Graham ML, Mutch LA, Rieke EF, Kittredge JA, Faig AW, DuFour TA, et al. Refining the high-dose streptozotocin-induced diabetic nonhuman primate model: an evaluation of risk factors and outcomes. Exp Biol Med (Maywood). 2011;236):1218-1230.

37. Badell IR, Russell MC, Cardona K, Shaffer VO, Turner AP, Avila JG, et al. CTLA4Ig prevents alloantibody formation following nonhuman primate islet transplantation using the CD40-specific antibody $3 \mathrm{~A} 8$. Am J Transplant. 2012;12:1918-1923.

38. Wijkstrom M, Kirchhof N, Graham M, Ingulli E, Colvin RB, Christians $\mathrm{U}$, et al. Cyclosporine toxicity in immunosuppressed streptozotocindiabetic nonhuman primates. Toxicology. 2005;207:117-127.

39.Rood PP, Bottino R, Balamurugan AN, Smetanka C, Ezzelarab M, Busch J, et al. Induction of diabetes in cynomolgus monkeys with high-dose streptozotocin: adverse effects and early responses. Pancreas. 2006;33:287-292.

40.He S, Chen Y, Wei L, Jin X, Zeng L, Ren Y, et al. Treatment and risk factor analysis of hypoglycemia in diabetic rhesus monkeys. Exp Biol Med (Maywood). 2011;236:212-218.

41. Shibata S, Kirchhof N, Matsumoto S, Sageshima J, Hiraoka K, Ansite J, et al. High-dose streptozotocin for diabetes induction in adult rhesus monkeys. Transplant Proc. 2002;34:1341-1344.

42.Jin X, Zeng L, He S, Chen Y, Tian B, Mai G, et al. Comparison of single high-dose streptozotocin with partial pancreatectomy combined with low dose streptozotocin for diabetes induction in rhesus monkeys. Exp Biol Med (Maywood). 2010;235:877-885.

43.Dufrane D, Van Steenberghe M, Guiot Y, Goebbels R-M, Saliez A, Gianello P. Streptozotocin-induced diabetes in large animals (pigs/primates): role of GLUT2 transporter and beta-cell plasticity. Transplantation. 2006;81:36-45.

44.Kavanagh K, Flynn DM, Nelson C, Zhang L, Wagner JD. Characterization and Validation of a Streptozotocin-Induced Diabetes Model in the Vervet Monkey. J Pharmacol Toxicol Methods. 2011;63:296-303. 